\title{
Editorial
}

\section{Al, Situatedness, Creativity, and Intelligence; or the Evolution of the Little Hearing Bones}

\author{
Eric Dietrich \\ Program in Philosophy, Computers, and Cognitive Science \\ Binghamton University
}

Good sciences have good metaphors. Indeed, good sciences are good because they have good metaphors. Al could use more good metaphors. In this editorial, I would like to propose a new metaphor to help us understand intelligence. Of course, whether the metaphor is any good or not depends on whether it actually does help us. (What I am going to propose is not something opposed to computationalism -- the hypothesis that cognition is computation. Noncomputational metaphors are in vogue these days, and to date they have all been equally plausible and equally successful. And, just to be explicit, I do not mean "IQ" by "intelligence." I am using "intelligence" in the way Al uses it: as a semi-techical term referring to a general property of all intelligent systems, animal (including humans), or machine, alike.)

What is it that we prize most highly about intelligence? What is the essence of intelligence? It is this: the ability to go beyond the information given (I refer the reader to Jerome Bruner's classic paper "Going beyond the information given," (Bruner, 1957)).

I think this captures our intuition that somehow intelligence is the ability to see beyond what's there. The further one can see, the more intelligent one is. Let me explain a bit further by paraphrasing F. C. Bartlett:

whenever any system interprets evidence from any source, and its interpretation contains characteristics that cannot be referred wholly to direct sensory observation or perception, then that system is intelligent. 1

Inferencing is the classic way to go beyond the information given (Bartlett, 1951; Bruner, 1957). But it is not the only way. The metaphor I am going to propose is another way to go beyond the information given.

Let us explore this definition of intelligence for while to see where it leads us. Then we will 
turn to the metaphor I am proposing. (I am aware that "going beyond the information given" is not really a definition in a technical sense. But, it is a distillation of some of our intuitions about what intelligence is. That is all we need here.)

Our definition violates some researchers' cherished notions about intelligence. Because they can make inferences, our definition includes such things as expert systems and similar computer programs which many in cognitive science and artificial life want to exclude from the set of intelligent systems. Furthermore, our definition excludes some "systems" that some in cognitive science and artificial life would want to call intelligent (at least, minimally, anyway). For example, paramecia and like animals are excluded because they do not go beyond -- or far enough beyond -- the information given. When a paramecium bumps into an obstacle, it reverses its cilia, backs up, and sets off again. It avoids the obstacle only if its orientation fortuitously changed enough while it was backing up. If not, then it when it starts forward again, it bumps into the obstacle again. It will happily bump into the obstacle indefinitely (well maybe not "happily," but it sure never looks like a creature learning and then planning a path around an obstacle). The odd thing about this is that building a robot as robust as a paramecium would not be that easy. So, on the one hand, some things satisfy our definition which nevertheless seem very stupid (expert systems), and other things which seem smart -- at least we can't easily replicate them, yet -don't satisfy our definition. What's wrong? Perhaps our intuitive definition of intelligence is incorrect?

No, I think our definition is just fine. Something deeper is causing the unhappy fit between our abstract definition of intelligence and the things which we think ought to satisfy it.

The problem is that our definition of intelligence does not take situatedness into account. "Situatedness" is the latest, controversial buzzword sweeping the fields of Al and cognitive science (other related terms include "situated action" and "situated cognition"). There is a fair amount of dispute about what "situated" means, what it means to be situated, and which robots or systems are or are not situated. Since we need some sort of definition of "situatedness" to continue our discussion, I present a reasonably good definition from a recent review of From Animals to Animats:

Situatedness: The production of competent behavior from minimal (often decentralized) control systems in tight sensory-motor loops with the environment (Brand et al. 1995). 
Paramecia get along in the natural world: they eat, excrete, reproduce, and sometimes avoid obstacles; expert systems do not. Paramecia, by existing and interacting with the world, carve out a niche in it -- what cognitive ethologists call an Umwelt: the perceptually selected part of the natural world that is biologically meaningful to the organism or system. Expert systems and the like don't seem to have an Umwelt. In short, paramecia are situated, expert systems are not. I think what we are noticing when we notice that expert systems do not seem intelligent though they satisfy our definition of intelligence is that they are not situated. We really have two intuitive definitions of intelligence: one is something like "going beyond the information given," and the other is something like "getting along in the natural world." Expert systems and similar computer programs satisfy the first, but not the second, and paramecia, ducks, squids, and humans (in fact all members of the animal kingdom) satisfy the second, but not always the first.

I think that having these two competing definitions is a good thing, and that seeing that intelligence seems to pull apart from being situated is arguably one of Al's important discoveries (although a discovery that Al has not explicitly and publicly acknowledged as a discovery). Indeed, that Al has succeeded in separating intelligence from situatedness (although until now unbeknownst to everyone) is probably why situatedness was introduced as an important new concept. Those researchers that champion the cause of situatedness (researchers like Brooks, Agre, Chapman, Stein, Beer, Suchman, and many others) have either decided that "getting along in the natural world" is the better definition of intelligence or that building a system that can robustly go beyond the information given requires that one first build a system that can negotiate some corner of the natural world, in other words that the two definitions require each other.

Here is another perspective on this matter. If we grant that a mind is something with a myriad cognitive and perceptual dimensions (leaving aside the notion of situatedness, for the moment) then one of Al's great successes (scientific Al, that is) is the realization that we can explore many these dimensions independently of each other, and some of them more or less one and a time. Planners, expert systems, natural language front-ends, analogical reasoners, casebased reasoners, and various connectionist systems are all systems by which Al researchers explore and experiment with a few dimensions of mindfulness at a time. None of these "distilled systems" has a mind (at least one could reasonably believe this), yet all are important for incrementally developing a theory of mind and eventually building a mind. In focussing on distilled systems Al is simply doing what all sciences do -- breaking up their subject matter into manageable pieces, theorizing about the pieces, and then hoping that the theories can be 
recombined to produce a theory of the whole. (Of course, another of Al's great successes (engineering $\mathrm{Al}$, that is) is the discovery that many of these distilled systems are useful in their own right.)

Now we can see another way to phrase the discussion between the situated types (i.e., cognitive scientists and Al researchers who champion the cause of situatedness) and their more classical colleagues: situated types are betting that experimenting with distilled systems is not the best methodology for understanding cognition and the mind, rather, they are betting on the strategy of starting from very simple, but situated robots, and building up. It is an open question which will win (if either), but certainly the best strategy is to pursue both methodologies in parallel. 2

For now, let's assume that we can distinguish between intelligence, abstractly conceived, and the notion of being situated. With this distinction, let me present the metaphor for intelligence that I promised you. I'm just going to dive in; I'll explain the relevance of the metaphor after I've presented it.

There are three bones in the middle ear of mammals. They are responsible for transferring sound from the ear drum to the oval window on the cochlea (the inner ear). The bones are called the hammer, the anvil, and the stirrup, in order from ear drum to oval window (the German word for these three bones means "little hearing bones.") These ear bones evolved from jaw bones and gill arches in early fish (gill arches are bones that support and hold open gill slits). The stirrup evolved from a gill arch just behind the jaw and the other two bones (the hammer and anvil) evolved from jaw bones. (All jaw bones may have evolved from gill arches -- the earliest fish had no jaws, they had jawless mouths, but they did have gill arches; jaws and gill arches have similar structure and developmental origins). We will focus on the evolution of the stirrup (see Gould, 1990, from where most of this discussion is taken, and see also Allin, 1975).

As fish developed jaws, the gill arch just behind the jaw bones (what was probably the second gill arch counting from the front of the fish towards the tail) became the hyomandibular: a bone that functions as a brace between the braincase and the jaw. In functioning as a brace, the hyomandibular naturally lay near the inner ear. And since it was bone, it naturally conducted sound well -- all bones do; this is simply due to physics and what they are made of. So, in fish, the hyomandibular eventually acquired (at least) two jobs: head brace and sound conductor (it probably had (and has) a respiratory function, too). Though fish "hear" primarily through organs in their side, they can no doubt detect some sound through their hyomandibular. The 
hyomandibular is thus overemployed.

As land animals evolved, the jaw and brain case became fused into the skull, so the hyomandibular was no longer needed to brace them. The hyomandibular thus lost its susceptibility to evolutionary pressures directed towards building a better brace. The bone was "free" to vary more widely (this happens sometimes with organs that have lost their primary function). Those variations that enhanced its role in hearing were selected for (better hearing is almost always a plus -- except possibly in crowded apartment complexes), and eventually the stirrup evolved. For a while during this evolution, the hyomandibular was a redundant brace. It was still functioning as a brace even after the solid skull formed. (All of this is documented in the fossil record; see Gould, 1990, and Allin, 1975).

Thus we see the role redundancy and overemployment have in evolution. Evolution is not solely a process of selecting the best organ or structure for a given job from a vast array of alternatives, more or less randomly arrived at. Instead, evolution often moves along paths laid out by overemployment, and then only when the organ's old job is accounted for by redundancy (or made obsolete for other reasons).

Overemployment and redundancy are fascinating. They are not odd, fringe facts about evolution; they are ubiquitous. More importantly, they are likely responsible for evolution's creativity. Overemployment and redundancy are due to a remarkable, and I suspect profound, fact about our universe: nothing, no bit of matter or energy, can have one and only one function. Everything has accidental properties and hence multiple, accidental functions. This fact is crucial to the evolution of complexity. As Gould puts it:

If each organ had only one function (performed with exquisite perfection), as each person has but one vote, then evolution would generate no structural complexity, and bacteria would rule the world. But we (and our fellow creatures of elaboration) are here by virtue of slop, multiple use, and redundancy. (1990, pp. 17-18)

I think it is instructive to view the creativity of evolution as a metaphor for the creativity of the mind. Specifically, I think it is instructive to view the hyomandibular and the evolution of the stirrup as a metaphor for creativity and concept use in cognition.

Human creativity is one of most important and interesting aspects of human cognition. And 
to date, we know very little about it. The good news is that studying creativity is becoming respectable in the cognitive sciences (in May of 1995, I attended a terrific workshop on creativity at Texas A\&M University, run by Tom Ward, Steven Smith, and Jyotsna Vaid, and sponsored by Texas A\&M and the American Psychological Association). Humans are indeed creative, but so is evolution. I am proposing that some of the aspects of evolution which make it creative, i.e., redundancy and overemployment (what Gould called multiple use, above), are also the very aspects of cognition which in part make us creative. The idea is this: information represented in the brain (say, in the form large state vectors) carries more information than it needs to to perform its required cognitive function, and this is true of perceptual information as well as conceptual information. So a given concept of yours, say, cat, carries more information than just the information which enables you to think about cats when cat is activated. There is more to a concept than what it denotes.

Another way to put this idea is to say that the brain represents some of its information explicitly -- this is, so to say, the "intended" semantic interpretation of the percept or concept (cats, in the example above) -- and some of its information implicitly. Hence information represented in the brain is in some interesting sense ambiguous; concepts have multiple, related contents some of which are explicit and some of which are implicit. This implicit information is usually some abstraction of the explicit information in the concept. But it is nevertheless implicit because there are myriad ways a given concept might be abstracted; they can't all be explicitly represented. Which few of these myriad ways become explicit depends on which other thoughts the given concept is involved with at the time. So, for example, as you watch a thick fog slowly and quietly work its way up the harbor and into town you might be reminded of a cat quietly walking home. The implicit information encoded in cat (and in fog and your perception of the encroaching fog) is what allows the fog to remind you of a cat. But it is only abstract information: you don't actually think you are seeing a cat when you watch the fog come in. (We actually know something about implicit information and its dynamics. Our knowledge comes from research on analogy and conceptual similarity. Check out Barsalou (1989), Gentner and Wolff (in press B), Gentner, Ratterman, Markman, and Kotovsky (in press A), and Hofstadter and Mitchell (1994), Medin, Goldstone, and Gentner (1993).)

The metaphor, then, is that at least some creativity in humans results from our concepts somehow carrying more information than they explicitly represent, and that some of this implicit information is made explicit when concepts and percepts interact.

If you are looking for a natural process that can go beyond the information given, then 
evolution must be your first choice -- in part because we understand so well how it manages to go beyond the information given. However, evolution is not usually regarded as creative, at least not in the way humans are creative. But the metaphorical relation between intelligence and this aspect of evolution seems to me to relatively fecund; it is well worth pursuing. And besides, we need the metaphors. 


\section{Endnotes}

1. Here's the actual quotation from Bartlett. “... whenever anybody interprets evidence from any source, and his interpretation contains characteristics that cannot be referred wholly to direct sensory observation or perception, this person thinks" (Bartlett, 1951). According to this definition everyone and every thing thinks whenever he, she, or it does anything with evidence. This seems right.

2. There is much more that could be, and needs to be said about the relation between classical Al and situated $\mathrm{Al}$ (and between those two and connectionism). For starters, some classical Al researchers flatly deny that situatedness is important to understanding minds, while some situated types flatly deny that anything classical types study, e.g., knowledge representation, is useful for understanding minds. And of course, I heard some connectionist side with the situated types, but insist that neural nets are the best way to achieve situatedness. All this discussion is good. In fact, the discussion has at times been rather heated. This is also good. When a field is engaged in a heated discussion with itself, usually some important, interesting change is afoot. The interested reader could begin exploring situatedness and its role in Al and cognitive science by checking out the special volume of Artificial Intelligence, vols. 72 and 73 . Bickhard and Terveen (1995), Hutchins (1995), and Thelen and Smith (1994) give a flavor of the range spanned by research on situatedness. 


\section{References}

Allin, E. F. (1975). Evolution of the mammalian middle ear. Journal of Morphology 147, 403-438. Barsalou, L. (1989). Intraconcept similarity and its implications for interconcept similarity. In S. Vosniadou and A. Ortony (Eds.) Similarity and Analogical Reasoning, 76-121. Cambridge: Cambridge Univ. Press.

Bartlett, F. C. (1951). Thinking. Manchester Memoirs , 93 , 3 (The Clayton Memorial Lecture, 1951).

Bickhard, M. and Terveen, L. (1995). Foundational Issues in Artificial Intelligence and Cognitive Science : Impasse and Solution. Elsevier.

Brand, M., Prokopowicz, P., and Elliot, C. (1995). Review of From Animals to Animats: Proceedings of the First International Conference on Simulation of Adaptive Behavior. Artificial Intelligence 73, 307-322.

Bruner, J. S. (1957). Going beyond the information given. in J. S. Bruner (Ed.) Contemporary Approaches to Cognition. Cambridge, MA: Harvard Univ. Press.

Gentner, D., Ratterman, M., Markman, A., and Kotovsky, L. (in press A). Two forces in the development of relational similarity. In T. Simon and G. Halford (Eds.) Developing Cognitive Competence: New pproaches to process modeling. Hillsdale, $\mathrm{NJ}$ : Lawrence Erlbaum.

Gentner, D. and Wolff, P. (in press B). Metaphor and knowledge change. In A. Kasher and Y. Shen (Eds.), Cognitive Aspects of Metaphor Structure, Comprehension and Use.

Hofstadter, D. and Mitchell, M. (1994). The Copycat Project: A model of mental fluidity and analogy-making. In K. Holyoak and J. Barnden (Eds.) Advances in Connectionist and Neural Computation Theory, v 2 : Analogical connections. Norwood, NJ: Ablex.

Gould, S. J. (1990). An earful of jaw. Natural History 3 (March), 12-23.

Hutchins, E. (1995). Cognition in the Wild. Cambridge, MA: MIT Press.

Medin, D., Goldstone, R., and Gentner, D. (1993). Respects for similarity. Psychological Review 100: 254-278.

Thelen, E. and Smith, L. (1994) A Dynamic Systems Approach to the Development of Cognition and Action. Cambridge, MA: MIT Press. 